\title{
O ENSINO DA ASSISTÊNCIA EDUCATIVA DE ENFERMAGEM
}

\author{
Maria Jacira N. D. Silva (*)
}

\begin{abstract}
INTRODUÇÃO. A importância da assistência educativa da enfermagem.
\end{abstract}

A tese de que a educação é processo básico para o trabalho de saúde não pode ser posta em dúvida - não só livros ou autores o demonstram mas, também, a experiência profissional daqueles que militam em tal campo. Nenhum programa de saúde, principalmente nos países em que certas enfermidades preveníveis continuam afetando uma grande parte da população dispensa, portanto, o concurso da educação. Não obstante a imagem que o público, e mesmo - médico, ainda façam da profissão, conservando a imagem da "mulher jovem, vestida de branco, serena e confiante em si mesma, que cumpre suas ordens, atende ao paciente fisicamente, o a nima e à sua família", (1) enfermagem significa também despertar o indivíduo e sua família para obter os meios de prevenir as doenças, promover e recuperar a saúde, o mais rápido possível, por seus próprios meios. E procura, como diz um autor (2), "assistí-lo em suas necessidades básicas e torná-lo independente desta, através da educação".

Existem muitas e variadas oportunidades para a assistência educativa de enfermagem através da orientação:

- do paciente que vai ser submetido a intervenção cirúrgica, e daquele que após a alta, no domicílio, prosseguirá o tratamento proposto pelo médico;

(*) Assistente. Enfermagem Preventiva. Escola de Enfermagem da USP.

(1) - LIPTON, E. - El nuevo papel de la enfermera en el equipo de salud. Boletim de la Oficina Sanitária Panamericana, 56 (1): 55-66, enero, 1964.

(2) HORTA, W. A. - Conceito de enfermagem. Revista da Escola de Enfermagem da USP, 2 (2): 1-5, setembro, 1968. 
- de gestantes e puérperas a respeito dos cuidados específicos;

- à população em geral, sobre as medidas de conservação e promoção da saúde.

Ensinar, pois, conhecimentos e habilidades que visem preparar o estudante de enfermagem para atividades educativas é de capital importância para melhorar a qualidade da assistência de enfermagem.

\section{O ENSINO DA ASSISTENCIA EDUCATIVA DE ENFERMAGEM NA ESCOLA DA USP}

Em artigo recentemente publicado (3) mostramos que a educação sanitária tem tido a importancia que merece, dentro da Escola de Enfermagem da USP.

E focalizada em diferentes disciplinas e matérias do currículo e hâ uma tendência para a integração desta nos diversos aspectos do atendimento de enfermagem. Por outro lado, mostramos, no mesmo trabalho, que a escola tem procurado ministrar esses conhecimentos de maneira correlacionada, tentando melhorar, cada vez mais, a aprendizagem e levando o aluno a atender o paciente de modo integral. Até a presente data, a educação sanitária tem sido ministrada pela Disciplina Enfermagem de Saúde Pública (4) e sempre procuramos fazer com que as experiências dos alunos neste setor ,se iniciassem no primeiro ano do curso, a fim de que incluíssem atividades educativas nos seus primeiros contactos com os pacientes, no campo. Inicialmente os docentes da Disciplina Fundamentos de Enfermagem, responsáveis pelos alunos, no campo, procuravam por em prática, os conhecimentos de Educação Sanitária, já adquiridos. Durante os anos subsequentes, a educação sanitária era continuamente integrada pelos alunos, na maioria dos estágios em clínicas e ambulatórios do hospital.

Entretanto, embora tudo isso venha sendo feito há bastante tempo ,os programas eram sempre modificados com a finalidade de melhorar, os aspectos deste ensino. Em 1969, com o apoio e a colaboração da Disciplina Fundamentos de Enfermagem, reformulamos o programa (anexo II), de tal forma que o programa qua era

(3) SILVA, M. J. N. D. - Sugestōes para maior integração da educação sanitária no curso de graduação em enfermagem. Revista da Escola de Enfermagem da USP., 2 (1): 39-60, mar. 1968.

(4) Atualmente, após a reforma universitária, denominada "Enfermagem Preventiva", do Departamento de Enfermagem Médico-Cicúrgica. 
ministrado anteriormente passou a constar de quatro unidade e o ensino da unidade IV constitui a experiência que relatamos neste trabalho.

O Programa foi reformulado tendo, em vista:

- o ensino teórico-prático, continuou a ser ministrado de maneira correlacionada com outras disciplinas do programa para $011^{\circ}$ ano, como era feito anteriormente;

- a Disciplina Fundamentos de Enfermagem continuou a responsabilizar-se, no campo, pela aplicação de conhecimentos e habilidades adquiridas sobre Educação Sanitária;

- os problemas educativos ligados à assistência de enfermagem continuaram merecendo consideração especial dos docentes, no sentido de aprofundar conhecimentos para melhor aplicação dos mesmos;

- a ênfase maior foi dada à metodologia do processo educativo na saúde; ao invés de desenvolvimento de habilidade em técnicas de ensino, procuramos intensificar no ensino, o desenvolvimento de habilidades de comunicação, porquanto estas poderiam servir de maneira mais eficiente, nos outros anos. quando os alunos teriam progressivamente a oportunidade de aplicá-las nas experiências de campo;

- a maior modificação, entretanto, deu-se na utilização dos métodos de ensino, os quais foram dentro do possível, menos expositivos com maior participação dos alunos e sobretudo relacionando o assunto novo com a experiência de vida de cada um.

As modificações introduzidas foram baseadas nos resultados de experiências anteriores, os quais nem sempre correspondiam aos objetivos esperados. Por exemplo, a necessidade de ministrar conhecimentos e experiências educativas antes do período de estágio no hospital, para preparar os alunos com relação ao cuidado integral, com já foi dito, dificultava a exposição do assunto, pela falta da vivência dos mesmos com relação aos problemas de saúde e de conhecimentos científicos a fim de formar um conteúdo razoável para poder transmitir e, por conseguinte, desenvolver habilidades. Para compensar essa deficiência, os temas escolhidos, por exemplo, para - treino das técnicas, eram relacionados à própria vida do estudante na escola (alimentação, estudo, recreação, atividades extracurriculares, etc.). Não nos sentíamos satisfeitas, entretanto. $O$ nú- 
mero de alunos matriculados no primeiro ano vinha, ano a ano, aumentando, dificultando êsse aspecto prático. Por outro lado, os assuntos escolhidos não despertavam interesse nos estudantes, assim como a prática que só podia ser feita, devido às dificuldades já mencionadas, em sala de aula.

Procuramos, então, dar ao aluno, como tentativa de melhorar a situação anterior, e sob a forma de trabalho de grupo, a oportunidade de viver uma experiência educativa a partir de uma situação real, selecionadas de maneira a não exigir do mesmo os conhecimentos científicos que ainda não tivera. Isto, não só para que se desenvolvesse o hábito de trabalho em grupo, mas, também, para que fosse solucionado o problema de número excessivo de estudantes. Demos então oportunidade ao aluno para identificar problemas relacionados à educação sanitária e para que tentasse planejar uma ação educativa, sentindo a importância e a responsabilidade da enfermagem perante o mesmo.

Para essa seleção de problemas no campo, contamos com a colaboração do pessoal de enfermagem dos campos de estágio utilizados pela escola (5).

A classe, de 52 alunos, foi dividida em 3 grandes grupos, aproveitando-se a divisão feita para outras aulas práticas do programa (Anatomia, Microbiologia, etc.). Esses, ainda foram sub-divididos em grupos menores, com um número de estudantes proporcional ao tipo de trabalho que iriam executar e as possibilidades do campo.

A primeira parte do programa, constou de uma aula expositiva para toda a classe, versando sobre a importância da comunicação na aprendizagem e da ação educativa da enfermagem, além do processo e os princípios gerais da comunicação no processo de educação para a saúde.

Após a aula, os estudantes, por meio de um roteiro (anexo 2) procuraram, observando situações reais, verificar a comunicação entre as pessoas. Fizeram, em média, duas observações cada um, num total de 104 observações.

(5) Hospital das Clínicas da Faculdade de Medicina da USP., Centro de Saúde G. Paula Souza; Faculdade de Saúde Pública; USP; ATOMP -Osasco- Area de treinamento em medicina Preventiva-Convênio Departamento de Medicina Preventiva, FMUSP, Cadeira de Fnfermagem de Saúde Pública da EEUSP e Prefeitura do Município de Osasco, SP. 
Em seguida, numa reunião com toda a classe, onde os resultados obtidos foram analisados em conjunto, procurou-se avaliar a observação dos alunos, fazendo-os relatar suas experiências e dificuldades além da análise das respostas ao roteiro.

Embora houvesse algumas falhas, achamos que a experiência foi boa para a aprendizagem, analisando-se posteriormente seus trabalhos práticos e a própria avaliação feita pelos alunos em relação ao método do professor e à sua aprendizagem.

Na aula subsequente, foi feito um estudo dirigido, que a nosso ver preencheu bem o objetivo de introduzir assunto novo, relacionando-o com experiências de vida dos estudantes (anexo 3).

Esse estudo, foi feito em grupos de discussão, sendo as conclusões dos alunos anotadas, corrigidas pelo professor, devolvidas e comentadas em classe. O conteúdo dessa aula versava sobre conceituação, objetivos, princípios básicos e métodos da educação para a saúde.

Em prosseguimento ao programa, os grupos receberam orientação para o trabalho prático, que consistia em observar, no campo, uma situação problema, como já dissemos. Foi dado um roteiro para o planejamento do trabalho (que já foi modificado para o ano seguinte), tornando-se mais detalhado, devido às dificuldades encontradas pelos alunos com relação ao primeiro (anexo 4).

Não houve oportunidade para que todos os grupos executassem seus respectivos planos, por falta de tempo, mas apenas o de um dos grupos. Essa última experiência foi realizada aproveitando-se a vacinação antitetânica de 1400 crianças de um grupo escolar da área de treinamento já mencionada. Como a Disciplina Fundamentos de Enfermagem desejava introduzir experiência em vacinação para estudantes do primeiro ano, foi planejado, em conjunto com a nossa, que é responsável pela supervisão e manutenção desta área de treinamento na comunidade, um programa que integrasse os objetivos de ambas.

Após o planejamento e execução de uma parte do programa, os alunos, em sala de aula, expuseram seus trabalhos, havendo oportunidade para troca de experiências e avaliação em conjunto. Os trabalhos além do plano educativo, incluiam a produção de um recurso audiovisual simples e econômico que viesse objetivar o ensino proposto pelos mesmos. Para a confecção dêste, tivemos ajuda do Laboratório Audiovisual da Escola que está equipado e com técnico preparado para ajudar nêsse setor. 
A avaliação do rendimento escolar dos alunos foi feita, no final, por meio de uma prova, que constou da resolução de uma situação forjada, mas semelhante à encontrada nos trabalhos práticos e alguns testes. Os alunos, também fizeram a avaliação do programa, através de um questionário (anexo 5). 50 alunos $(96 \%$ da classe) compareceram a esta avaliação, cujos resultados são dados a seguir.

1 - Quanto a terem os objetivos da unidade sido atingidos ou não, dos 50 alunos que responderam ao questionário:

- $49(90,8 \%)$ acharam que os objetivos propostos foram atingidos; dêstes, $47(90,4 \%)$ justificaram as opiniões apresentadas na tabela I

- 1 aluno $(9,2 \%)$ achou que os objetivos não foram atingidcs porque "o programa fixou-se somente no plano tórico" (?)

TABELA 1

Razões pelas quais os alunos consideram que os objetivos foram atingidos.

\begin{tabular}{|c|c|c|}
\hline RAZOES & N. ${ }^{\circ}$ & $\%$ \\
\hline $\begin{array}{l}\text { Visão ampla e objetiva dos problemas de educação sa- } \\
\text { nitária, a maneira de solucioná-los desenvolvendo ca- } \\
\text { pacidade de observação }\end{array}$ & 13 & 27,6 \\
\hline $\begin{array}{l}\text { O aluno entrou em contacto com situações reais e não } \\
\text { imaginárias }\end{array}$ & 11 & 23,4 \\
\hline $\begin{array}{l}\text { Parece que se aprendeu a tratar de problemas de edu- } \\
\text { cação para a saúde }\end{array}$ & 9 & 19,2 \\
\hline Houve aplicação da teoria na prática & 3 & 6,2 \\
\hline $\begin{array}{l}\text { Houve motivação, o tempo foi bem aproveitado e os } \\
\text { ensinamentos foram úteis }\end{array}$ & 3 & 6,2 \\
\hline $\begin{array}{l}\text { Através dos trabalhos dos colegas, tivemos oportunida- } \\
\text { de de verificar a aprendizagem geral }\end{array}$ & 2 & 4,2 \\
\hline $\begin{array}{l}\text { Tivemos oportunidade, no trabalho prático, de observar } \\
\text { o interesse do público }\end{array}$ & 2 & 4,2 \\
\hline $\begin{array}{l}\text { Encontramos facilidade em resolver problemas sem de- } \\
\text { corar regras }\end{array}$ & 1 & 2,1 \\
\hline Outros & 3 & 6,2 \\
\hline TOTAL & 47 & 100,0 \\
\hline
\end{tabular}


2 - Com relação ao método empregado para o ensino, as opiniões foram as seguintes: 43 (86\%) acharam-no BOM, 6 (12\%) classificaram-no REGULAR e $1(2 \%)$ achou-o MAU.

As razões em número de 45 , apresentadas por alunos que acharam o método BOM, figuram na tabela II

\section{TABELA II}

Razões pelas quais os alunos consideram BOM o método empregado.

RAZOEES

N. ${ }^{\circ} \%$

Partiu de uma situação real, dando oportunidade de conhecer problemas da comunidade

Houve oportunidade de se fazer um trabalho prático, de aprender a resolver problemas

Não foi cansativo, mas prático e de fácil entendimento

Houve participação ativa do aluno e oportunidade de se "aprender fazendo"

Se se apresentarem situações semelhantes, o aluno será capaz de resolver

Houve bastante liberdade, o aluno trabalhou à vontade e sempre havia orientação quando solicitada

Despertou bastante interesse

Atingimos os objetivas traçados

Oportunidade de trabalho de grupo e discussão

Houve aprendizagem

24,4

Foi bem objetivo principalmente na apresentação final dos trabalhos

Os motivos, em número de 7, apresentados por alunos que consideraram o método REGULAR, são apresentados na tabela III 
TABMA III

\begin{tabular}{lc}
\hline \multicolumn{1}{c}{ RAZOES } & N.o \\
\hline Não aplicamos o nosso plano & 2 \\
A coleta de dados por nós mesmas, seria melhor & 1 \\
Pouco tempo para muito trabalho & 1 \\
Faltou mais trabalho de campo & 1 \\
Faltou orientação em certos pontos do trabalho \\
Trabalho de grupo nem sempre dá resultados, pois alguns co- \\
legas não trabalham bem e prejudicam o grupo \\
\hline \multicolumn{1}{c}{ TOTAL } & 1 \\
\hline
\end{tabular}

O aluno que achou o método MAU, não deu as razões

3 - Com relação às dificuldades encontradas, os resultados foram os seguintes:

- $16(32 \%)$ encontraram dificuldades no estudo dirigido

- $33(66 \%)$ encontraram dificuldades nos trabalhos práticos

As dificuldades relativas a estudo dirigido e a trabalhos práticos são discriminados respectivamente nas tabelas IV e V

\section{TABETA IV}

Dificuldades encontradas pelos alunos no estudo dirigido.

\begin{tabular}{ll}
\hline Dificuldades & N. \\
\hline
\end{tabular}

Por ter sido utilizado a discussão de grupo onde é difícil chegar-se a conclusōes pois os pontos de vista são diferentes 4 Falta de objetividade do aluno e dificuldade em encontrar as soluções e focalizar o assunto 4 Relacionar um problema de saúde com outros conhecimentos 2 Por ser o métado diferente do usual, sendo uma primeira experiência

Coordenar os trabalhos práticos 


\section{TABELA V}

Dificuldades encontradas pelos alunos no trabalho prático.

\begin{tabular}{ll}
\hline Dificuldades & N. \\
\hline
\end{tabular}

No planejamento e na confecção de material audio visual 10 No diagnóstico do problema e no planejamento da ação educativa 7 Por ser uma primeira experiência No trabalho de grupo Pela falta de dados Pelo tempo exíguo $\mathrm{Na}$ compreensão dos objetivos Dificuldades normais de um trabalho educativo Somente no início

$4-16$ alunos $(32 \%)$ apresentaram sugestões para a melhoria do método, que figuram na tabela VI

TABELA VI

Sugestões apresentadas pelos alunos, para a melhoria do método.

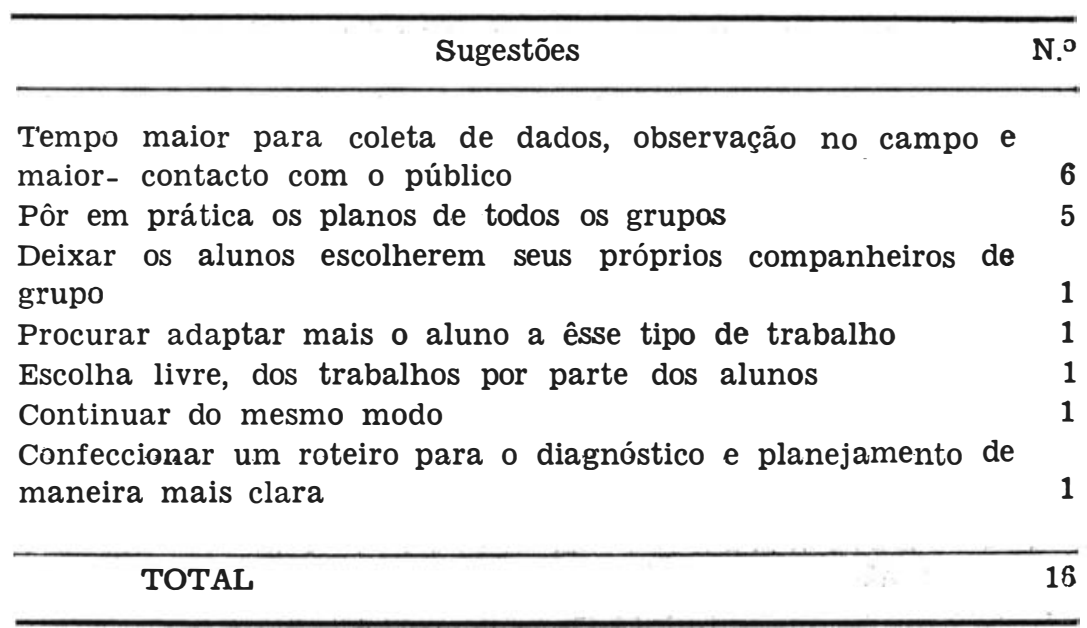




\section{RESUMO E CONCLUSÕES:}

A educação é básica para o trabalho de saúde e a enfermagem constitui-se ponto chave, devido à atuação direta e por longo tempo, junto aos indivíduos sãos e doentes que serão focalizados por um programa de saúde.

A metodologia da educação para a saúde, as técnicas da comunicação educativa, são aspectos que não podem deixar de ser ensinados num curso de enfermagem. Procuramos mostrar neste trabalho, que a aprendizagem do aluno se faria muito mais profundamente se o ensino se fizesse de maneira integrada mas que, por dificuldades várias, não se conseguiu ainda no nosso meio. Procuramos mostrar, também, que o importante é dar êsses aspectos logo no início do curso para que o aluno tenha oportunidade de po-los em prática, através dos anos subsequentes. Também, é mais importante, nêste momento do curso, dar-lhe meios para que aprenda a identificar o problema educativo dentro da assistência integral de enfermagem, planejar a ação adequada e saber as bases da comunicação eficiente para cacia caso. A habilidade em se comunicar, só se desenvolverá adequadamente, após algum treino junto aos pacientes o que deverá ocorrer, se for intensificada nos anos subsequentes. 


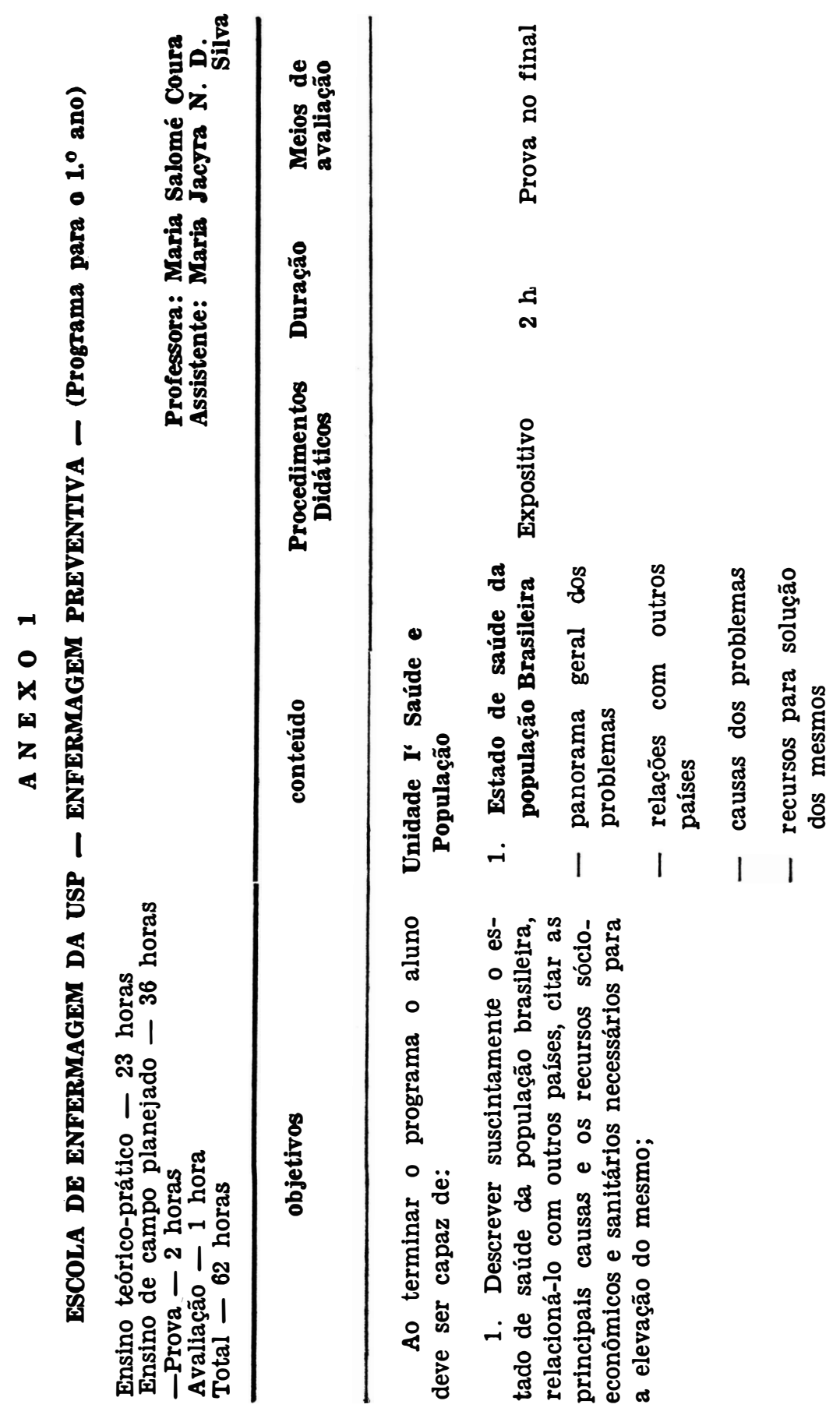




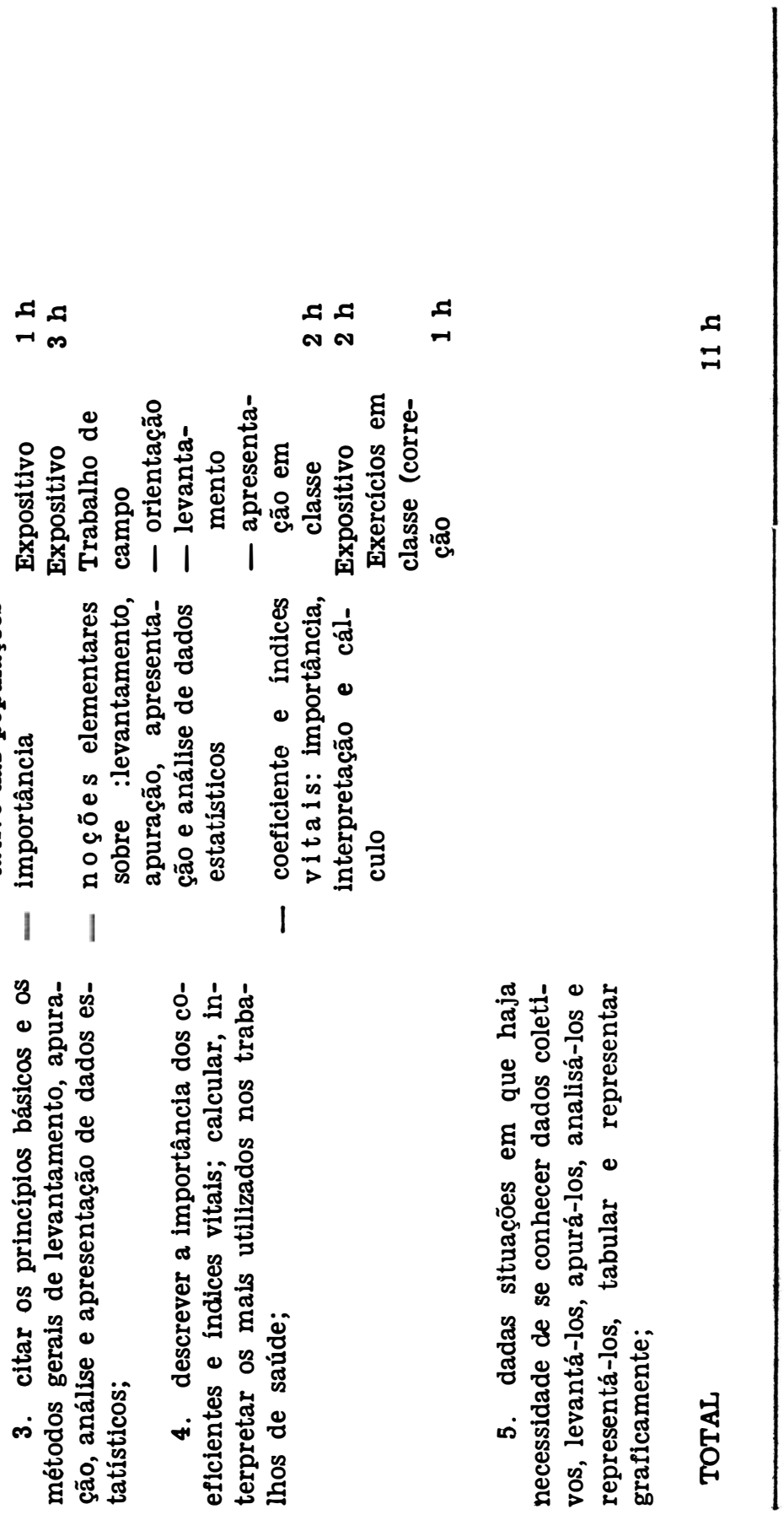




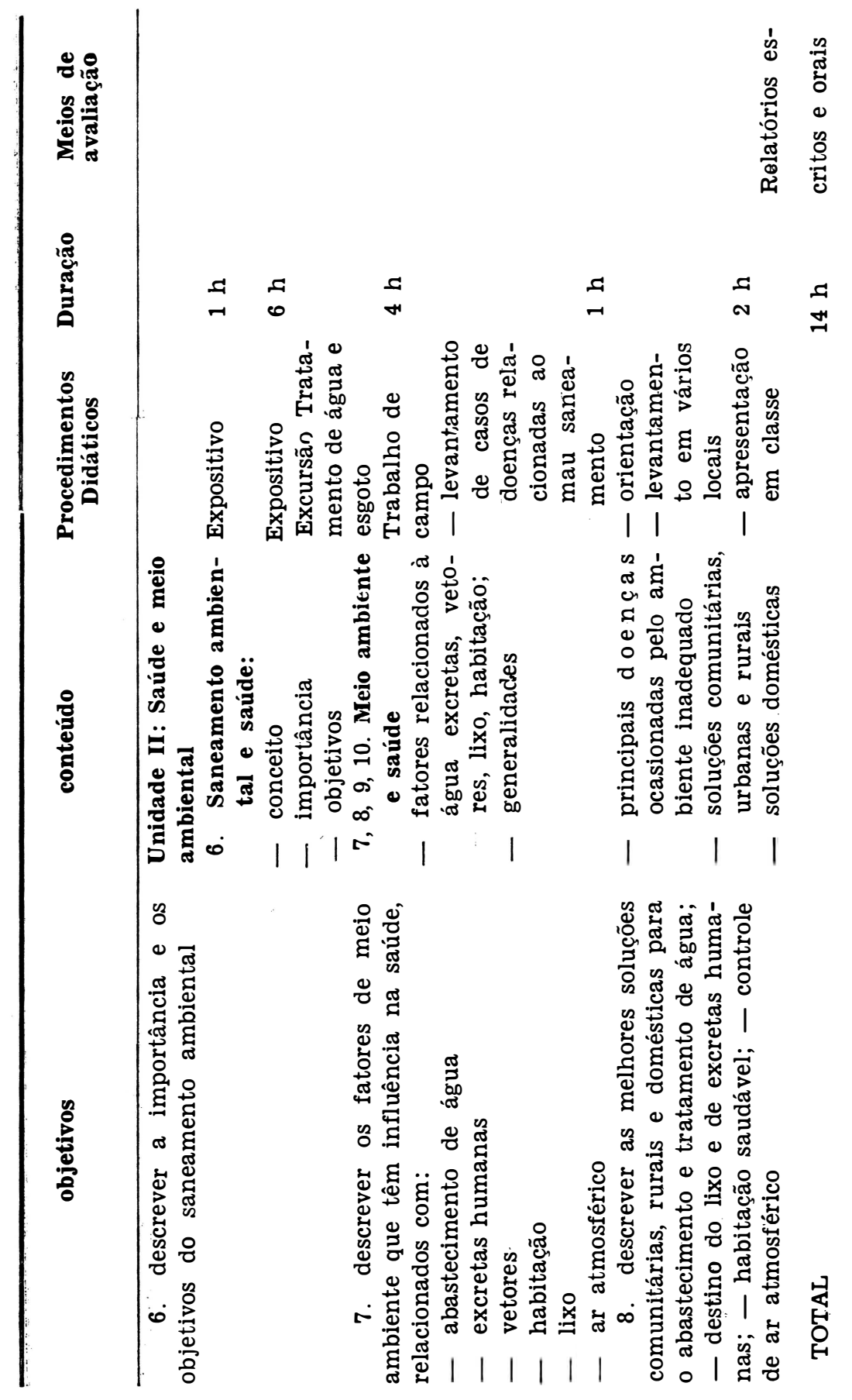




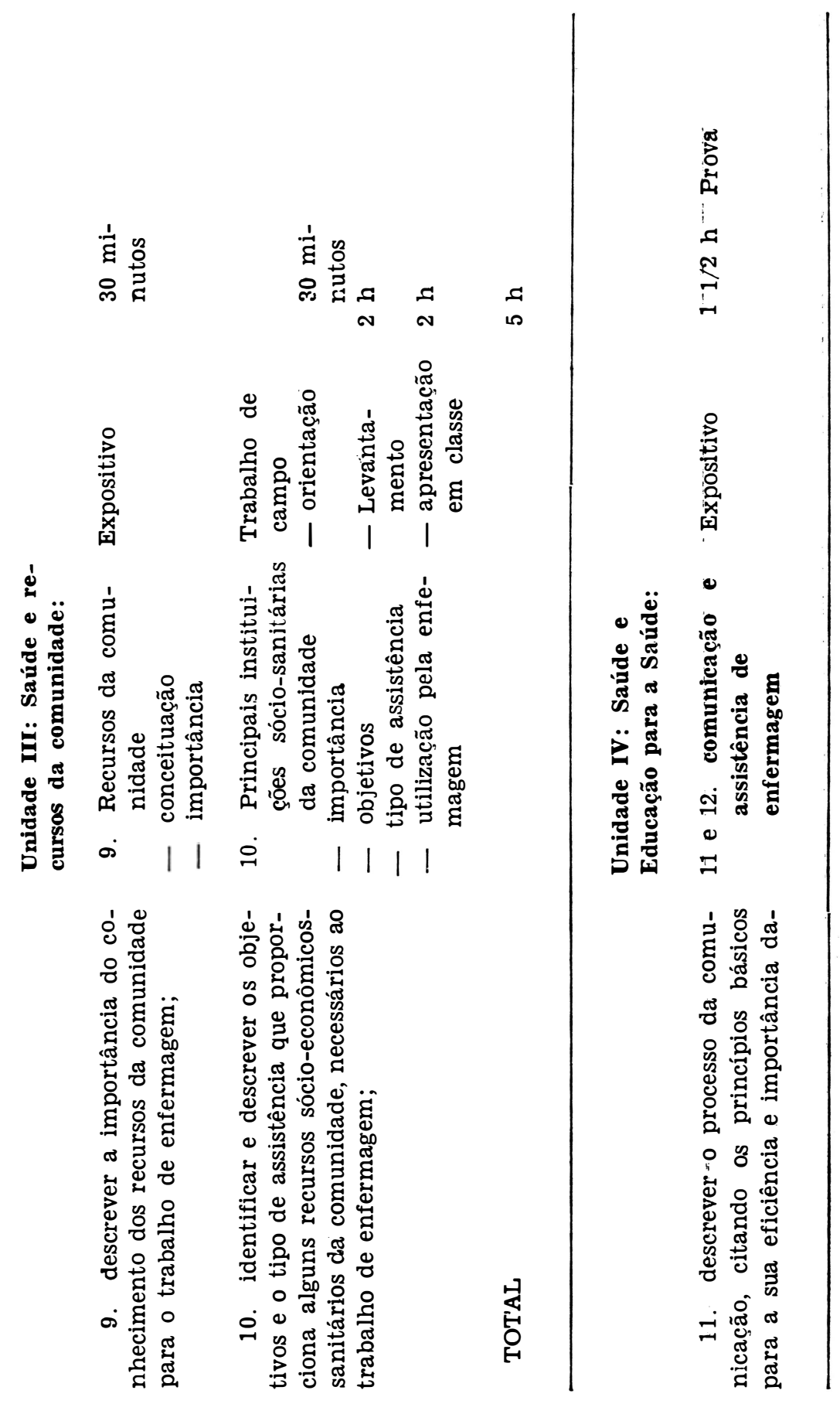




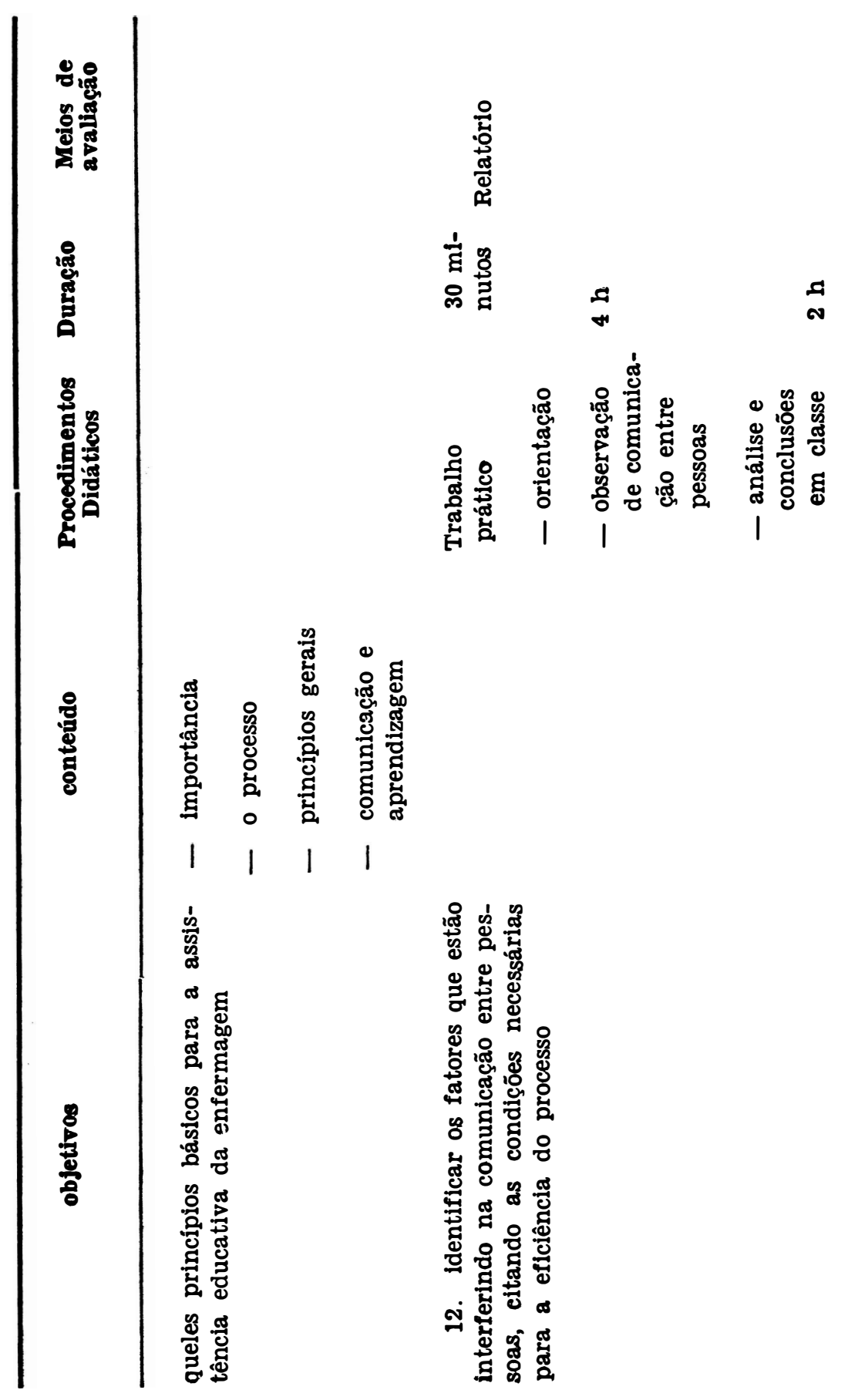


怘

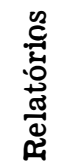

a 1 a

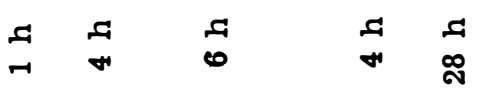

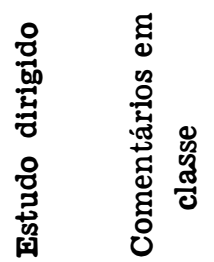

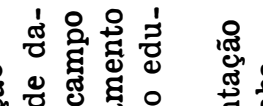

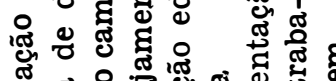

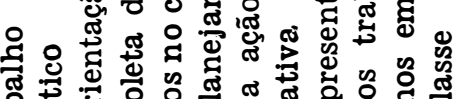

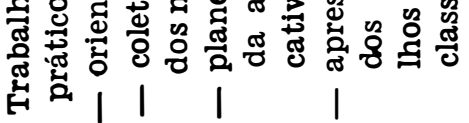
莺

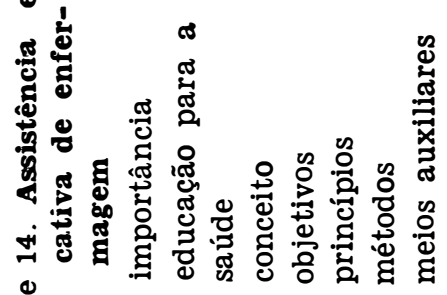

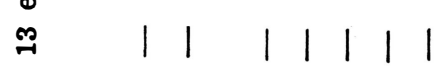
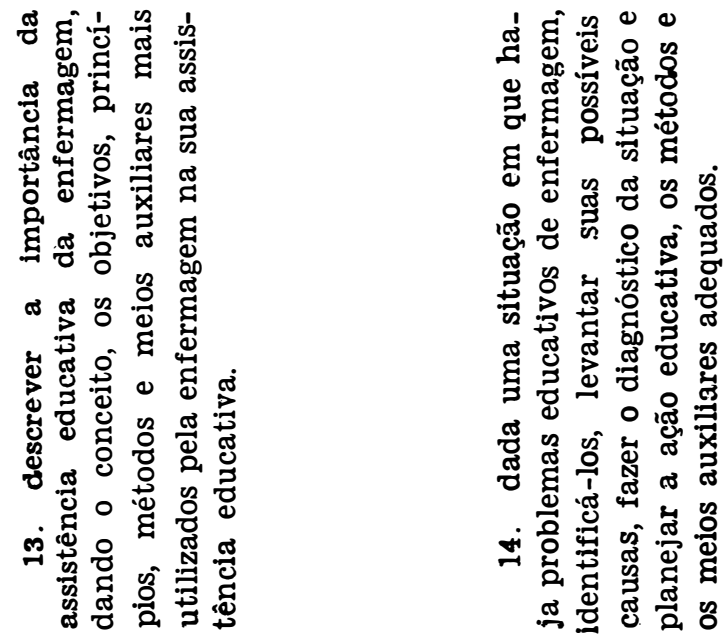
A N E X O 2

COMUnicaÇão e eduCaÇão para a saUde

RELACIONADOS A FONTE E AO DESTINATÁRIO

Roteiro para observação e avaliação dos fatores que interferem na eficiência da comunicação entre duas pessoas (Ver instruções no final do roteiro)

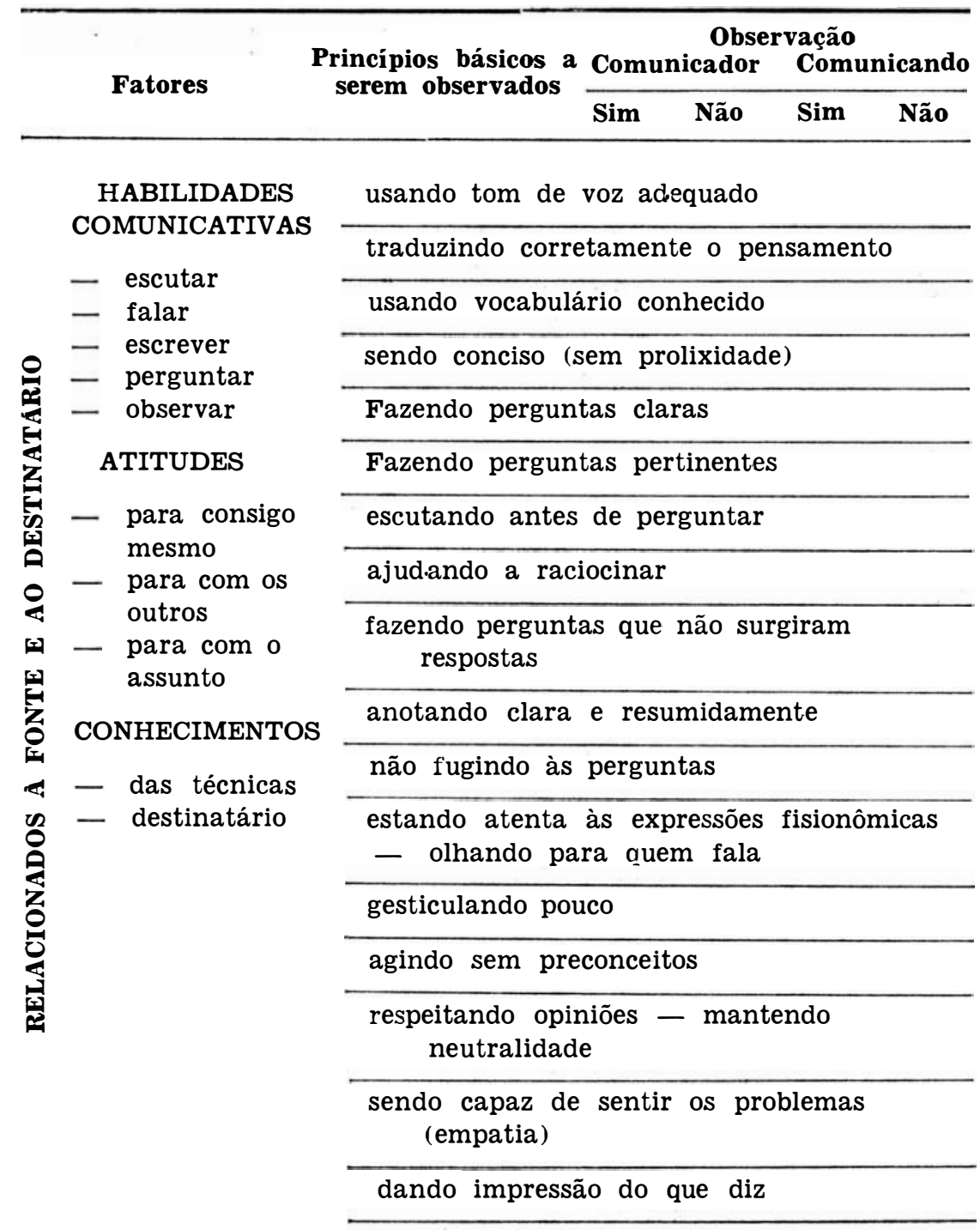




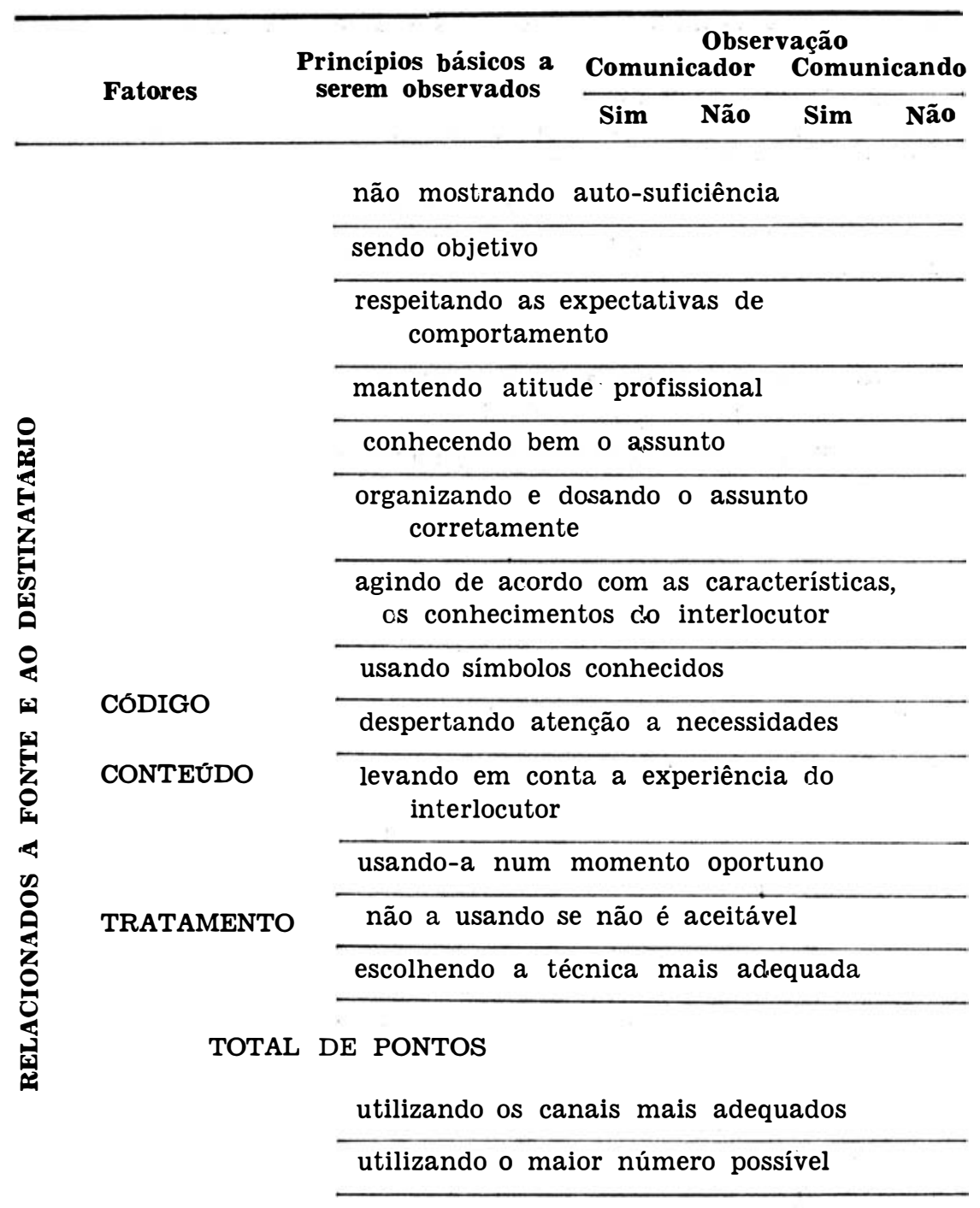

TOTAL DE PONTOS

\section{Instruções}

1. Observe, durante duas horas pessoas em comunicação falada, por gestos ou escrita (em conversa, entrevista, aula, demonstração, etc.). 
2. Escolha uma fonte ou comunicador de cada vez e acompanhe durante certo tempo a sua interação com outras pessoas (destinatário ou comunicando), mesmo que estas sejam várias, mas que naquele momento estejam em comunicação.

3. Analise cada processo, enquanto as pessoas forem as mesmas. Assinale:

- com um X na coluna SIM e NAO, se, de acordo com sua observação, os princípios foram seguidos, ou não.

- com um traço (-) na coluna SIM, se não houve necessidade ou oportunidade de aplicá-los.

4. Faça tantas fôlhas, quantos foram os processos observados, uma para cada observação.

\section{ANEXO 3 \\ ESCOLA DE ENFERMAGEM DA USP \\ PROGRAMA DE ENFERMAGEM PREVENTIVA \\ 1.0 Ano - FUNDAMENTOS DE ENFERMAGEM}

Unidade IV - Saúde e educação para a saúde

Estudo dirigido: conceito, princípios básicos e metodologia da educação para a saúde.

Segundo os peritos da OMS, (1) as funções da enfermagem variam consideravelmente de um local para outro e estão condicionadas às características sócio-econômicas-sanitárias de cada país. Reconhecem entretanto que a função educativa deve estar sempre incluída em qualquer cuidado de enfermagem o que deve ser comum aos profissionais de enfermagem de todo o mundo. Isto porque a natureza das relações da enfermeira com pacientes adultos ou crianças coloca-a numa posição verdadeiramente invejável para grangear a confiança das pessoas, compreender seus problemas pessoais e familiares e ter mais base para um trabalho educativo.

A enfermagem, segundo Wanda Horta (2) "é a arte de assistir ao ser humano no atendimento de suas necessidades básicas, de torná-lo independente desta assistência, através da educação, de re-

(1) OPAS - Comission de expertos en enfermeria: informe de la 1a. Sesion - Washington, DC, OPAS, 1951 - Série de informes ténicos n. ${ }^{\circ} 24$.

(2) HORTA, W. A - Conceito de Enfermagem. Revista da Escola de Enfermagem da USP, 2 (2): 1-5, set. 1968. 
cuperar, manter e promover sua saúde em colaboração com outros profisisonais".

teste estudo dirigido visa levá-lo ao conhecimento do conceito, principios básicos e a metodologia usada na educação para a saúde.

Leia com atenção cada item e procure respondê-lo suscintamente e com suas próprias palavras.

1. Conceitue, após ler Luiz Alves de Mattos, no seu "Sumário de Didática Geral", $5^{\mathrm{a}}$. edição (até página 65 do capitulo VII) 0 que entende por:

- ensino

- aprendizagem

2. Após ler a tracução mimeografada do artigo de W. Griffithe, "O processo educativo no trabalho de saúde", (até o final da página 5), responda o seguinte:

- o que entende por processo educativo no trabalho de saúde?

- Quais são as fases ou etapas necessárias para que haja mudança de comportamento com relação a conhecimentos, atitudes, hábitos de saúde?

- o que é percepção? Quais são as percepções em relação a conhecimentos, atitudes e hábitos de saúde de algumas pessoas que você conhece, inclusive de sua família? Cite 3 .

- no seu trabalho educativo junto aos pacientes, o seu problema maior será criar percepções a respeito da saúde e não tanto mudá-las; por que?

- muitas vezes você sentirá que embora falando muito com as pessoas sôbre práticas corretas de saúde, documentadas com fatos ou farto material ilustrativo, elas se recusam a mudar seu comportamento com relação às mesmas. Você conhece algum exemplo dentro da sua experiência de vida? Então cite-o e diga o que você acha que influi para que isto aconteça.

- cite apenas, quais são as necessidades biológicas, sociais e culturais que podem influenciar a mudança de comportamento, conhecimento, hábitos e atitudes com relação a saúde. Você conhece algum caso em que a motivação, foi responsável pela educação de alguém? Cite-o.

- durante o nosso trabalho como enfermeiros, veremos que muitas vezes as intenções das pessoas a quem ensinamos são boas e temos quase que certeza de que as mesmas seguirão o que recomendamos. Entretanto, vemos que deixam de completar o que pretendem fazer. É o caso, por exemplo de uma criança cuja mãe tem a intenção de levá-la ao 
médico para um exame mas que nunca o faz, não estando melhor que uma outra mãe que ignora a importância do mesmo exame. Como você acha que deve agir para que a mesma, passe da intenção para a ação?

3. Lendo o mesmo artigo, à pág. 4, diga:

- quais são os principais tipos de métodos utilizados para a mudança de comportamento em relação a saúde? Descreva suscintamente cada um deles.

4. Após ler:

- apostila sôbre Técnicas Educativas e Material Audiovisual da Escola de Enfermagem da USP;

- a publicação da OMS "Educacion Higienica del publico, no apendice, o capítulo sôbre "Exemplos de métodos e meios"

- o livro do Dr. Brito Bastos sôbre "Educação Sanitária", pág. 371 a 379.

Cite 4 métodos e 5 tipos de material audiovisual utilizados em educação sanitária.

5. Após ler as mesmas publicações, assinale com um $\mathbf{X}$ a resposta certa, dos seguintes testes:

5.1 as palestras, as conferências e as aulas expositivas devem ser utilizadas:

- quando queremos favorecer o espírito de grupo, pelo intercâmbio de idéias dos membros que assistem, entre sí;

- para informar, apenas, sôbre um assunto, pois o público tende a passividade, não tendo oportunidade de participar;

- quando queremos mudar comportamentos rapidamente.

5.2 o método de contacto individual (por exemplo a entrevista) é mais útil:

- quando se trata de mudanças difíceis, que levam em conta problemas pessoais e o indivíduo não reage bem em grupo;

- quando o tempo é curto para agrupar muitas pessoas juntas;

- nem uma e nem outra.

5.3 a demonstração, é um método que emprega, principalmente, o seguinte princípio da aprendizagem:

- o de "aprender fazendo"

- o da "motivação"

- o da "repetição"

5.4 a discussão de grupo deve ser utilizada principalmente, na educação para a saúde:

- quando contamos com elementos capazes de falar bem frente a grupos; 
- quanäo queremos ganhar tempo, ensinando várias pessoas ao mesmo tempo;

- quando queremos que a aprendizagem seja pela troca de experiências e os problemas se resolvem democraticamente.

6. Depois de ter lido o artigo de Griffiths até a pág. 4, para poder responder às perguntas do item 2, você estará capacitada a formular, com suas palavras, os princípios que você considera básicos para a educação de seus pacientes em matéria de saúde. Para que fique mais completo, leia também o folheto "Como as pessoas aprendem". Mas seja suscinta e claro!

\section{ANEXO 4 \\ ESCOLA DE ENFERMAGEM DA USP ENFERMAGEM PREVENTIVA \\ (Programa 'para o 1.0 ano}

Unidade IV: Educação para a saúde

Roteiro para plano de assistência educativa de enfermagem

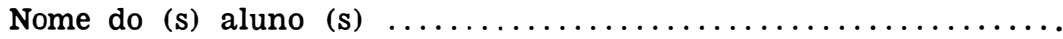

Data: Classe

1 - ANAMNESE (estudo e levantamento da situação): após entrar em contacto com o problema educativo, estude e especifique as características do grupo ao qual se destina a sua ação:

- idade, sexo, raça, grau de instrução, ocupação, religião, nível econômico cultura, etc.

- necessidades sentidas, percepções, interêsses, etc.

- recursos humanos e materiais existentes: serviço e pessoal de saúde, outros recursos da comunidade, canais de lidederança, meios de comunicação, etc.

- etiologia (causas) e proporções do problema, fatôres condicionantes prováveis que o agravam, e suas consequências para a saúde.

2 - DiAgNóstiCo: após o estudo e levantamento; chegue a um diagnóstico educativo do problema apresentado, dizendo se ele se resume a:

- falta de informação?

- informação não científica? 
- crenças, atitudes, hábitos negativos, opostos?

- percepção defeituosa?

- ausência de motivação ou interêsse?

- desorganização grupal

- indecisão para agir?

- outros?

3 - TRATAMENTO: após identificar o problema educativo (diagnóstico) determine:

3.1 - os objetivos, isto é, qual o comportamento final desejado, a curto e a longo prazo;

3.2 - os métodos e os meios auxiliares que utilizará para objetivar o seu ensino, dando as razōes desta escolha.

Planeje e confeccione um tipo de material audiovisual, pelo menos, seguindo as seguintes etapas:

- determinando os objetivos para o qual se destina;

- determinando o momento e o local da apresentação;

- determinando a quantidade a ser produzida;

- fazendo um esboço ("lay-out") do mesmo;

- procurando testá-lo;

- produzindo-o de acôrdo com o seu plano;

3.3 - os meios de avaliação: đuue serão utilizados a curto e a longo prazo, para avaliar a eficiência da sua ação educativa.

Nota: apresente o plano por escrito, com a descrição das etapas que seguir no roteiro, anexando o material confeccionado, a bibliografia consultada, contendo as dificuldades encontracas para 'elaboração dêste trabalho. Planeje, também, uma apresentação para ser feita em classe, para suas colegas.

\author{
ANEXO 5 \\ ESCOLA DE ENFERMAGEM DA USP \\ ENFERMAGEM PREVENTIVA \\ (Fundamentos de Enfermagem $-10^{\circ}$ Ano) \\ Unidade IV - Saúde e Educação para a Saúde
}

\title{
AVALIAC̣̃̃o DOS ALUNOS
}

O nosso objetivo para esta unidade foi o de capacitá-los, através do estudo de uma situação real, no campo, a diagnosticar os problemas educativos existentes, dando suas causas e planejando 
a ação educativa através da escolha de métodos, meios auxiliares e de avaliação mais adequados. Responda as perguntas:

1. Você achou que os objetivos foram atingidos?

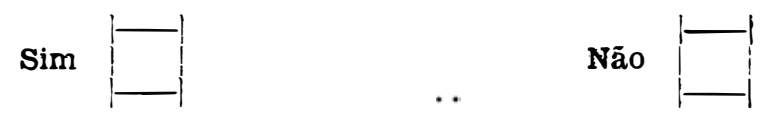

Por quê?

2. Você achou que o método empregado para o ensino, foi:

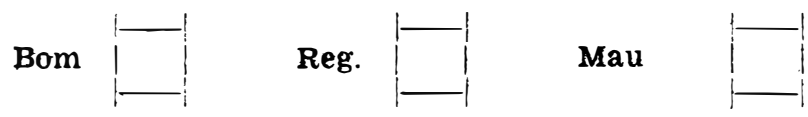

Por quê?

3. Você encontrou alguma dificuldade:

- No estudo dirigido?

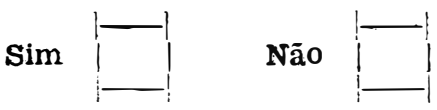

Quais?

— Nos trabalhos práticos?

Sim

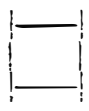

Não

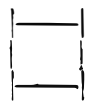

Quais?

4. Tem sugestões para melhoria do método?

Sim

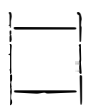

Não

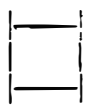

Quais? 


\section{BIBLIOGRAFIA}

- BAGgalay, O. La función de la enfermera en la educación sanitaria del publico. Boletin de la Oficina Sanitária Panamericana, 46 (6): 560-563, jan, 1959.

- BASTOS, B. N. C. - Educação Sanitária. Fundamentos, objetivos e métodos. Ed. preliminar, Guanabara, FSESP, 1963.

- BERLO, D. - $\mathbf{O}$ processo da comunicação, $\mathbf{R}$. Janeiro - F. Cultura.

- CASTro, R. R. - O pediatra na educação sanitária da coletividade. Atualidades Médico-Sanitárias, (53): 1981-1994, jan/ mar. 1955.

- DART'Y, W. A. - La educacion sanitária como parte integrante de la atención total de enfermeria. Boletin de la Oficina Sanitária Panamericana.

- DERRIBERRI, M. - Educação Sanitária. Seus objetivos e métodos. (Tradução mimeografada de Angélica Franco, Prefeitura Municipal de S. Paulo).

- GRIFFITHS, W. - O processo educativo no trabalho de saúde. California'S Health, 15 (2) : dez. 1957. (Tradução mimeografada).

- HORTA, W. A. - Conceito de Enfermagem - Revista da Escola de Enfermagem da USP, 2 (2): 1-5, set. 1968.

- LIPTON, E. El nuevo papel de la enfermera en el equipo de salud. Boletin de la Oficina Sanitaria Panamericana, 56 (1): 55-66, jan, 1964.

- OPAS, Comission de expertos en enfermeria, informe de la $1 .^{\text {a }}$ session. Washington, D. C., OPAS, 1951 - Série de informes técnicos n. ${ }^{\circ} 24$.

- SILVA. M. J. N. D. - Sugestões para melhor integração da educação sanitária no curso de graduação em enfermagem. Revista da Escola de Enfermagem da USP, 2 (1): 39-60, mar. 1968. 